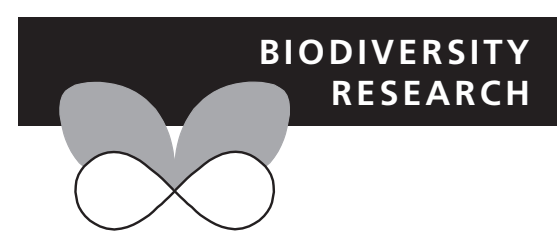

\title{
From current distinctiveness to future homogenization of the world's freshwater fish faunas
}

\author{
Sébastien Villéger ${ }^{1 \star}$, Simon Blanchet ${ }^{2,3}$, Olivier Beauchard ${ }^{4}$, \\ Thierry Oberdorff ${ }^{5}$ and Sébastien Brosse ${ }^{3}$
}

${ }^{1}$ Laboratoire Écologie des Systèmes Marins Côtiers (ECOSYM), UMR 5119 CNRSUM2-IRD-IFREMER-UM1, Place Eugène Bataillon cc 93, Montpellier 34095, France, ${ }^{2}$ Station d'Écologie Expérimentale du CNRS à Moulis, U.S.R 2936, Moulis 09200, France, ${ }^{3}$ CNRS, ENFA, UMR5174 EDB (Laboratoire Évolution et Diversité Biologique), Université Paul Sabatier, 118 route de Narbonne, Toulouse F-31062, France, ${ }^{4}$ Netherlands Institute for Sea Research (NIOZ), P.O. Box 140, Yerseke 4400 AC, The Netherlands, ${ }^{5}$ UMR "BOREA" (IRD 207, CNRS 7208, MNHN, UPMC), DMPA, Museum National d'Histoire Naturelle, 43 rue Cuvier, Paris Cedex 75231, France

${ }^{*}$ Correspondence: Sébastien Villéger, Laboratoire ECOSYM (UMR 5119), Place Eugène Bataillon cc 93; 34095 Montpellier, France.

E-mail: sebastien.villeger@univ-montp2.fr

\begin{abstract}
Aim Assessing the consequences of a future increase in non-native species introductions and native species extirpations on taxonomic similarity among fish faunas.
\end{abstract}

\section{Location World-wide.}

Methods We designed 42 scenarios of future species introductions and extirpations to simulate future fish composition for 1054 river basins. Using these simulated future compositions, we computed the change in taxonomic similarity among pairs of fish faunas from historical to future situation at the river basin, biogeographic realm and world scales.

Results According to all our scenarios, taxonomic similarity among fish faunas will strongly increase in the future at the three spatial scales considered. Fish faunas from the Southern Hemisphere, which are currently the less affected by taxonomic homogenization, are forecasted to show the steepest changes. Our scenarios also reveal that non-native species introductions will account for most of the predicted changes, whereas the effect of native species extirpations will be weak.

Main conclusions The predicted future taxonomic homogenization will blur the current high level of taxonomic dissimilarity among freshwater fish faunas, and therefore, imperil the conservation programmes based on beta-diversity mapping.

\section{Keywords}

extirpation, freshwater fish, introduction, non-native species, taxonomic similarity, taxonomic uniqueness.

\section{INTRODUCTION}

Non-native species introductions, combined with the extirpation of native species, are known to modify the similarity in species composition between assemblages (Olden, 2006; Olden \& Rooney, 2006). This problem has been addressed for more than 10 years on various taxa and in several places around the world (Rahel, 2000; Rooney et al., 2004; Clavero \& García-Berthou, 2006; Olden et al., 2008a; Spear \& Chown, 2008; Winter et al., 2009; Shaw et al., 2010; Villéger et al., 2011). Most of these studies reported an increase in taxonomic similarity between assemblages following native species extirpation and/or non-native species introduction. For instance, the taxonomic similarity between the world's freshwater fish faunas in river basins has increased on average by $0.5 \%$ over the past two centuries (Villéger et al., 2011). This overall trend towards regional and global taxonomic homogenization is nevertheless contrasted for several taxa, with some assemblages' pairs showing taxonomic differentiation (Shaw et al., 2010; Villéger et al., 2011; Hermoso et al., 2012).

All the studies that assessed temporal changes in taxonomic similarity are based on comparisons between current and historical situations. Current situation corresponds to present species composition, whereas historical situation refers to composition two centuries ago, that is, before human-induced changes in compositions through non-native introductions and extirpations of native species (Olden \& Rooney, 2006). Indeed, the industrial revolution of the 19th century was the starting point of a steep increase of human 
impacts on natural ecosystems (Butchart et al., 2010; Ellis et al., 2010) and of the development of a massive intercontinental trade responsible for most non-native species introductions (Taylor \& Irwin, 2004; Vander Zanden, 2005; Leprieur et al., 2008a; Blanchet et al., 2009). Although the patterns and determinants of changes in taxonomic similarity between assemblages from historical to current situation have been increasingly studied (Rahel, 2000; Olden \& Poff, 2004; Leprieur et al., 2008b; Spear \& Chown, 2008; Winter et al., 2009; Villéger et al., 2011; Hermoso et al., 2012), much less attention has been devoted to future trends (but see Duncan \& Lockwood, 2001; Olden \& Poff, 2004; Olden et al., 2008a; Matsuzaki et al., 2013), especially at large spatial scales. Yet, both native species extirpations and non-native species introductions are supposed to increase in the next decades under accelerated rates of climate change, resource exploitation, habitat change and global trade (Sala et al., 2000; Hulme et al., 2009; Clavero, 2011). For instance, species with a restricted geographic range and under direct anthropogenic threats (e.g. human harvesting) are the most prone to extirpation in the future (Baillie et al., 2004; Olden et al., 2006a, 2007). In addition, even if the development of national and international laws regulating the transport and introduction of alien species might reduce intercontinental faunal exchanges (McAusland \& Costello, 2004; Hulme et al., 2009), controlling non-native species spread after establishment remains of low efficiency for most taxa (Pimentel et al., 2005). Therefore, established populations of non-native species may continue to spread in the surrounding regions (Hulme et al., 2009; Clavero, 2011; Bradley et al., 2012). The composition of communities may thus substantially change in the next decades as well as taxonomic similarity between them. Forecasting the future changes in taxonomic similarity under both future extirpation and introduction processes, and especially assessing whether the current global trend towards homogenization will accelerate is thus an urgent conservation issue.

Here, we use a database on freshwater fish occurrences at the world scale to simulate future changes in taxonomic similarity between fish faunas from 1054 river basins under 42 scenarios of future introductions and extirpations. These scenarios were designed to test the future sensitivity of taxonomic similarity to three complementary factors: native species extirpation, non-native species introduction pressure and identity of the non-native species. We then compare these predictions with the observed current changes in taxonomic similarity and discuss the differences in these forecasted future changes among scenarios and among biogeographic realms.

\section{METHODS}

\section{Database}

We used a uniquely comprehensive database of freshwater fish species distributions containing freshwater fish species lists from 1054 river basins scattered throughout the world and covering more than $80 \%$ of Earth's continental surface (Brosse et al., 2013). For each of the 39,704 occurrences of 9722 fish species, the native, extirpated or established nonnative status is given (non-native species occurrences due only to fish stocking were not considered). Non-native species introductions were split into translocated species (when the species originated from the same biogeographic realm) and exotic species (when the species originated from another realm). We studied change in taxonomic similarity among fish assemblages at the world scale and in the six biogeographic realms: Afrotropical, Australian (including Oceania), Nearctic, Neotropical, Oriental and Palearctic (Villéger et al., 2011). Considering realms independently was motivated by their distinct history, fauna and human activities (Leprieur et al., 2008a, 2011; Blanchet et al., 2009).

\section{Simulating future composition of freshwater fish faunas}

To assess future levels of taxonomic similarity, we simulated future composition of freshwater fish faunas under 42 scenarios combining three variables (Table 1): introduction pressure (future number of non-native species fixed or varying with current species richness), identity of nonnative species (equal probability of introduction among non-native species or species specific probability of introduction dependent on the current frequency of occurrence of each non-native species) and native species extirpation (no extirpation or extirpations of all the species listed as threatened in the 2004 International Union For Conservation Of Nature (IUCN) Red List; Baillie et al., 2004).

\section{Introduction pressure}

The main aim of our simulations was to quantify the effect of a future increase in the number of non-native species occurrences on taxonomic similarity (Olden \& Poff, 2004; Olden et al., 2008a). We therefore simulated the addition of non-native fish species in river basins where they currently do not occur, following two different assumptions. In the first series of scenarios, the number of additional non-native species varied independently of the current species richness in the river basin, with five levels of increase: 1, 2, 5, 10 or 20 additional non-native species (Table 1). In the second series of scenarios, we accounted for potential effects of basin size and/or habitat diversity by simulating an increase in the number of non-native species proportionally to the current species richness in the river basin, again with five levels: 10 , $20,50,100$ or $200 \%$ of the current species richness (Table 1). The future levels of introduction pressure simulated are of the same order of magnitude than the current level of non-native species richness in the Nearctic and Palearctic realms (Clavero \& García-Berthou, 2006; Leprieur et al., 2008a; Olden et al., 2008a). For instance, there are 
Table 1 Summary of the scenarios of non-native species introductions and native species extirpations used in this study

\begin{tabular}{|c|c|c|c|}
\hline Species extirpated & $\begin{array}{l}\text { Choice of non-native species } \\
\text { introduced }\end{array}$ & $\begin{array}{l}\text { Number of non-native } \\
\text { species introduced }\end{array}$ & Scenario code \\
\hline \multirow[t]{20}{*}{ None } & \multirow{10}{*}{$\begin{array}{l}\text { Equiprobable choice among all } \\
\text { non-native species currently } \\
\text { present in the realm }\end{array}$} & \multirow[t]{5}{*}{$1,2,5,10$ or 20 species } & ExNo-InEa1 \\
\hline & & & ExNo-InEa2 \\
\hline & & & ExNo-InEa5 \\
\hline & & & ExNo-InEfa10 \\
\hline & & & ExNo-InEa20 \\
\hline & & \multirow{5}{*}{$\begin{array}{l}10,20,50,100 \text { or } 200 \% \\
\text { of current species richness }\end{array}$} & ExNo-InEp10 \\
\hline & & & ExNo-InEp20 \\
\hline & & & ExNo-InEp50 \\
\hline & & & ExNo-InEp100 \\
\hline & & & ExNo-InEp200 \\
\hline & \multirow{10}{*}{$\begin{array}{l}\text { Probability based on current } \\
\text { occurrence of non-native } \\
\text { species in the realm }\end{array}$} & \multirow[t]{5}{*}{$1,2,5,10$ or 20 species } & ExNo-InFa1 \\
\hline & & & ExNo-InFa2 \\
\hline & & & ExNo-InFa5 \\
\hline & & & ExNo-InFfa10 \\
\hline & & & ExNo-InFa20 \\
\hline & & \multirow{5}{*}{$\begin{array}{l}10,20,50,100 \text { or } 200 \% \text { of } \\
\text { current species richness }\end{array}$} & ExNo-InFp10 \\
\hline & & & ExNo-InFp20 \\
\hline & & & ExNo-InFp50 \\
\hline & & & ExNo-InFp100 \\
\hline & & & ExNo-InFp200 \\
\hline \multirow{20}{*}{$\begin{array}{l}\text { All species listed as threatened } \\
\text { in the } 2004 \text { IUCN Red List }\end{array}$} & \multirow{10}{*}{$\begin{array}{l}\text { Equiprobable choice among all } \\
\text { non-native species currently } \\
\text { present in the realm }\end{array}$} & \multirow[t]{5}{*}{$1,2,5,10$ or 20 species } & Ex04-InEa1 \\
\hline & & & Ex04-InEa2 \\
\hline & & & Ex04-InEa5 \\
\hline & & & Ex04-InEa10 \\
\hline & & & Ex04-InEa20 \\
\hline & & \multirow{5}{*}{$\begin{array}{l}10,20,50,100 \text { or } 200 \% \text { of } \\
\text { current species richness }\end{array}$} & Ex04-InEp10 \\
\hline & & & Ex04-InEp20 \\
\hline & & & EX04-InEp50 \\
\hline & & & Ex04-InEp100 \\
\hline & & & Ex04-InEp200 \\
\hline & \multirow{10}{*}{$\begin{array}{l}\text { Probability based on current } \\
\text { occurrence of non-native } \\
\text { species in the realm }\end{array}$} & \multirow[t]{5}{*}{$1,2,5,10$ or 20 species } & Ex04-InFa1 \\
\hline & & & Ex04-InFa2 \\
\hline & & & Ex04-InFa5 \\
\hline & & & Ex04-InFa10 \\
\hline & & & Ex04-InFa20 \\
\hline & & \multirow{5}{*}{$\begin{array}{l}10,20,50,100 \text { or } 200 \% \text { of } \\
\text { current species richness }\end{array}$} & Ex04-InFp10 \\
\hline & & & Ex04-InFp20 \\
\hline & & & Ex04-InFp50 \\
\hline & & & Ex04-InFp100 \\
\hline & & & Ex04-InFp200 \\
\hline \multirow{5}{*}{$\begin{array}{l}\text { All species listed as threatened } \\
\text { in the } 2014 \text { IUCN Red List }\end{array}$} & Equiprobable choice among all & 1 & Ex14-InEa1 \\
\hline & $\begin{array}{l}\text { non-native species currently } \\
\text { present in the realm }\end{array}$ & & \\
\hline & Probability based on current & 1 & Ex14-InFa1 \\
\hline & occurrence of non-native & & \\
\hline & species in the realm & & \\
\hline
\end{tabular}

already more than 10 non-native fish species in more than $10 \%$ of the river basins in Western Europe and USA (Leprieur et al., 2008a).

\section{Identity of non-native species}

In addition to testing the influence of the future non-native species introduction pressure, we assessed the influence of non-native species identity on future taxonomic similarity. Two assumptions were simulated (Table 1): (1) 'equiprobable introduction' where probabilities of future occurrences of non-native species are independent of current occurrence patterns of non-native species, (2) 'frequency-dependent introduction' where probabilities of future occurrences of non-native species depend on their current occurrence patterns at the realm scale. 
Under the 'equiprobable' assumption, non-native species added to a river basin were selected at random among the pool of non-native species in the realm to which the basin belongs.

Under the 'frequency-dependent' assumption, the random choice was weighted by current occurrence frequencies of nonnative species observed in the realm. This assumption implies that future occurrences of non-native species will be driven by two non-random processes: (1) the natural dispersal in neighbouring basins of the non-native species already established in numerous basins and/or (2) human-assisted introductions of species having an economic or recreational interest and which have already become successfully established in numerous basins. Indeed, the current pattern of non-native species occurrences clearly reflects human preferences for a few fish (Fig. S1), with only $9 \%$ of non-native fish species having been introduced in more than $10 \%$ of the river basins within a realm and more than $50 \%$ of non-native species having been introduced in a single river basin (Table S1). These non-native species, translocated within realms or imported from distant realms, are mainly large species voluntarily introduced for aquaculture and game fishing, and smaller species that have been transported for mosquito control or for ornamental purposes (Alcaraz et al., 2005; Blanchet et al., 2010; Gozlan et al., 2010; Britton et al., 2011; Clavero, 2011). Frequency-dependent scenarios also account for the potential differences in non-native species establishment success. Indeed, non-native species introduced in a new area need first to pass the local environmental filters acting on their survival and reproduction rates (e.g. temperature, predators and pathogens) to establish sustainable populations (Blackburn et al., 2011). Non-native species that successfully established in numerous basins at the realm scale are thus able to support a large range of abiotic and biotic conditions and may hence be able to succeed in other basins of the same realm. However, the contrary is not systematically true as a small number of occurrences may be due solely to recent introductions in a few places (Alcaraz et al., 2005).

For the two modalities of introduction, non-native species added to a river basin came from the current pool of nonnative species already found in the realm to which the basin belongs. This conservative choice was made to prevent unrealistic introductions. It is indeed impossible to accurately predict which species may become non-native in the future. Moreover, non-native species that are already established, including species translocated within a realm and those originating from other realms, would account for most of the non-native occurrences in the future (Alcaraz et al., 2005; Rahel, 2007). As a practical consequence, the number of additional non-native species introduced in a river basin was actually limited by the size of the non-native species pool of the realm to which the basin belongs (Table S1).

\section{Extirpation}

In parallel to the increase of non-native species richness, we simulated the effect of future extirpations of threatened native species (Olden et al., 2008a; Matsuzaki et al., 2013). We first tested two levels of extirpation (Table 1): (1) no species will be extirpated in the future; and (2) all the native species listed as 'threatened' (i.e. 'near threatened', 'vulnerable', 'endangered' or 'critically endangered') in the IUCN Red List (Baillie et al., 2004) will be extirpated (Olden et al., 2008a; Matsuzaki et al., 2013). These two levels of extirpation could be considered as extreme, but limiting the number of scenarios ensures keeping a manageable number of simulations. Even if the IUCN listing procedure may suffer from potential biases and limitations, the IUCN Red List remains the most objective and authoritative classification of species extinction risk (Rodrigues et al., 2006).

Threatened species were identified based on the 2004 IUCN Red List as this assessment was contemporary to the most recent fish occurrences included in the database. To assess the potential effect of changes in IUCN fish status since then, we also considered the extirpations of all species listed as threatened in the last version of the Red List (data downloaded from the IUCN website in March 2014). This sensitivity analysis was performed for the two scenarios being the most sensitive to species extirpations, that is, the two scenarios simulating the introduction of a single non-native species (selected at random or based on current introduction frequencies) (Table 1).

For each level of extirpation and each level of introduction pressure, the choice of additional non-native species (random or weighted by current frequency of species) was replicated 999 times in each fish fauna.

\section{Measuring change in taxonomic similarity}

We assessed the taxonomic similarity in the species composition of assemblages using the Jaccard's similarity index that measures the percentage of similarity in assemblage composition (Olden \& Rooney, 2006; Villéger \& Brosse, 2012). The Jaccard's similarity index $(J)$ is: $J=\frac{a}{a+b+c}$, where $a$ is the number of species shared by two assemblages and $b$ and $c$ are, respectively, the number of species present only in the first and second assemblage. $J$ equals zero when the two assemblages share no species $(a=0)$ and equals unity when they have identical species composition $(b=c=0)$.

We computed the taxonomic similarity in fish composition for each pair of river basins across the world for 'historical', 'current' and 'future' situations using Jaccard's similarity index (Olden \& Rooney, 2006; Villéger \& Brosse, 2012). 'Historical' refers to the past fauna with only native species and thus roughly corresponds to the pre-industrial period (i.e. before the 18th century), as industrialization and associated goods exchanges are recognized as the main drivers of fish introductions, mainly for aquaculture, fishing and ornamental purposes (Rahel, 2000; Leprieur et al., 2008a). 'Current' refers to present fauna with the nonnative species and without the native species that have been extirpated during the two last centuries (Villéger et al., 2011). 'Future' refers to simulated fauna given each 
of the future scenarios of fish introductions and extirpations.

We investigated change in taxonomic similarity at three complementary scales (Leprieur et al., 2008b; Villéger et al., 2011). At the global scale, we studied the change from the historical to the current and future situations in the distribution of taxonomic similarity values obtained for all the pairs of basins over the world, using four parameters; that is, mean, median, skewness and kurtosis. We also computed the proportion of basin pairs that show homogenization or differentiation between the historical and current situation and between the historical and future situation. In addition, we quantified taxonomic uniqueness as the proportion of basin pairs having no species in common (Rahel, 2000; Villéger et al., 2011). We conducted the same analyses at the realm scale by considering the pairs of basins belonging to each of the six biogeographic realms.

To analyse the change in taxonomic similarity within each river basin, we computed the difference in average similarity values between each river basin and the other basins belonging to the same realm for historical and current (or future) situations (Leprieur et al., 2008b). A positive value indicates an increase in average similarity through time, that is, taxonomic homogenization, whereas a negative value indicates a decrease in average similarity, that is, taxonomic differentiation (Olden \& Poff, 2003; Shaw et al., 2010; Villéger et al., 2011). The relative importance of extirpations, introductions and geography (realm) on the future changes in average taxonomic similarity at the basin scale were quantified using a generalized linear model. Simulations and statistical analyses were conducted with R (R Core Team, 2013).

\section{RESULTS}

\section{Future changes in taxonomic uniqueness}

Under all future scenarios of increasing non-native species introductions in river basins, taxonomic uniqueness will decrease quickly from its current level (Fig. 1a and see Fig. $\mathrm{S} 2 \mathrm{a}-\mathrm{d}$ in Supporting Information). For instance, the introduction of two additional non-native species selected according to the current non-native species occurrences (scenario (ExNo-InFa2') will lead to a decrease of taxonomic uniqueness (compared with historical situation) by more than $24 \%$ in all realms (Fig. 1a). With five additional non-native species (scenario 'ExNo-InFa5'), taxonomic uniqueness will be lower than $10 \%$ in all the realms and will decrease down to only $20 \%$ at the world scale (Fig. 1a). Under the alternative scenarios of increasing non-native species introductions, taxonomic uniqueness also shows a decreasing trend, which is, however, less steep when the future non-native species introductions do not depend on current frequency of occurrence of non-native species (Fig. S2a-d). Considering future extirpations of the species listed as threatened weakly affected these trends.

\section{Future changes in pairwise taxonomic similarity}

At world and realm scales, the mean taxonomic similarity among fish faunas is forecasted to increase under all future scenarios of increasing non-native species introductions (Fig. 1b, Fig. S2e-h). For instance, the introduction of five additional non-native species per river basin, selected according to the current non-native species occurrences (scenario 'ExNo-InFa5'), will lead to an increase in taxonomic similarity (compared to historical situation) by more than $2.4 \%$ in all realms and at the world scale (Fig. 1b). With ten additional non-native species per river basin (scenario 'ExNoInFa10'), taxonomic similarity will be higher than $10 \%$ in all realms, except in the Neotropical realm (9.3\%), and of ca. $7 \%$ at the world scale. Again the alternative scenarios of introduction and extirpation produced similar trends (Fig. $\mathrm{S} 2 \mathrm{e}-\mathrm{h}$ ), but the magnitude of the increase was lower in the scenarios simulating random future introductions of nonnative species.

At the river basin scale, changes in taxonomic similarity between fish assemblages showed contrasted patterns. Indeed, as for the average taxonomic similarity, the proportion of assemblage pairs that are expected to show homogenization in the future will increase quickly. For instance, adding five non-native species per river basin (scenario 'ExNo-InFa5') will lead to a pre-dominance of homogenization $(>75 \%$ in all realms, Fig. 1c). On the opposite, differentiation will become scarce. Although introducing only one or two additional non-native-species per river basin (scenarios 'ExNoInFa1' and 'ExNo-InFa2') will lead to a slight increase in the frequency of differentiation (Fig. 1d), differentiation will decline for higher introduction pressure. All the scenarios confirmed these trends even if once again non-random future introductions will produce steeper changes than random introductions (Fig. S3).

Additional statistics confirmed the trends towards taxonomic homogenization (Fig. S4). Indeed, the median of the pairwise taxonomic similarity values will also increase following increasing occurrences of non-native species (Fig. S4a-d). Meanwhile, the skewness and the kurtosis of this distribution will both decrease (Fig. S4e-l), indicating that the distribution of similarity values will become less right-skewed and less peaked (i.e. the proportion of extremely low similarity values will decrease).

\section{Future changes in mean taxonomic similarity per river basin}

Under all future scenarios of increasing native species extirpations and non-native species occurrences, homogenization will become more frequent and of higher magnitude at the river basin scale (i.e. increase in mean similarity between a fish fauna and the other faunas from the same realm). For instance, with only two additional non-native species per river basin (scenario 'Ex04-InFa2' in Table 1), more than $80 \%$ of the world freshwater fish assemblages will experience 

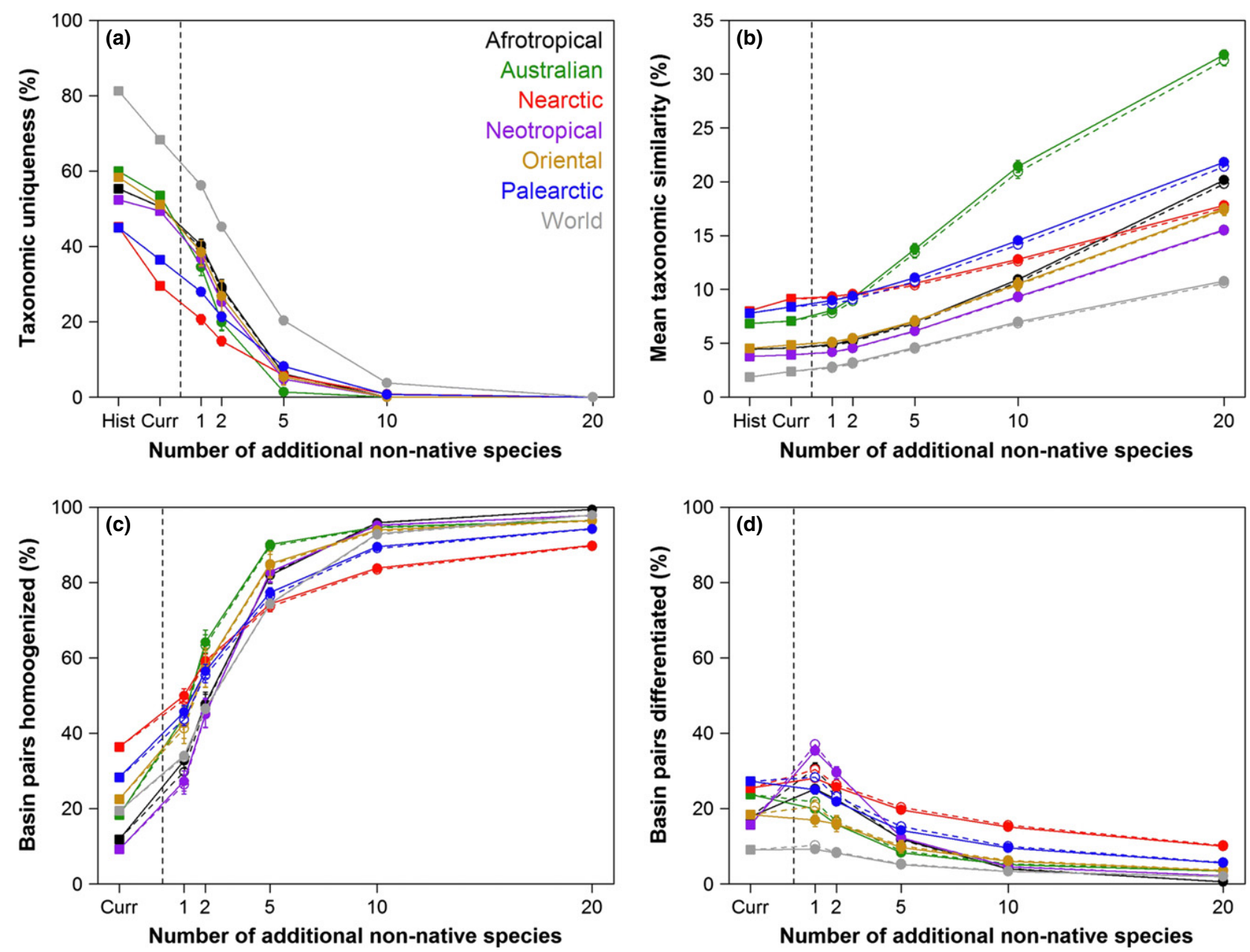

Figure 1 Current and future trends of taxonomic similarity among fish faunas for the six realms and for the world scale. (a) Taxonomic uniqueness among fish faunas (percentage of fish faunas pairs sharing no species). (b) Mean pairwise taxonomic similarity among fish faunas pairs (measured using Jaccard's similarity index). (c-d) Proportion of fish faunas pairs that exhibit taxonomic differentiation (i.e. decrease in taxonomic similarity) or homogenization (i.e. increase in taxonomic similarity) from historical situation. The left side of each plot shows the historical and current observed patterns, while the right side shows simulations of future trends under an increasing number of non-native species occurrences in each basin (from 1 to 20) with additional non-native species occurrences selected according to their current frequencies in each realm. Points represent mean values and the associated $95 \%$ confidence intervals. Filled symbols (and solid lines) represent scenarios considering both introduction and extirpation (scenarios 'Ex04InFa' in Table 1) while open symbols and dashed lines are for the scenarios considering only introduction (scenarios 'ExNo-InFa'). Open symbols, dashed lines and confidence intervals, although present are often hidden behind filled symbols and solid lines.

an increase in homogenization (Figs 2-3, Fig. S5) and with five additional non-native species per basin (scenario 'Ex04InFa5'), more than $10 \%$ of the fish assemblages will homogenize by more than $5 \%$ in all the realms to the exception of the Neotropical realm ( $5 \%$ of assemblages). Under this scenario, taxonomic differentiation will become scarcer and of lower intensity except for the Nearctic realm where the proportion of fish assemblages that differentiate will increase at the lowest level of introduction pressure (Figs 2-3, Fig. S5). At this scale, too, all scenarios produced similar predictions (Fig. 3, Fig. S5).

The F-statistic values of the GLM analysis computed at the river basin scale revealed that the changes in taxonomic similarity were mainly driven by the number of additional non-native species, the identity of the realm to which the basin belongs and the interaction of these two factors (Table 2). Extirpation did not play a significant role (Table 2). Changes in taxonomic uniqueness and taxonomic similarity in the six realms were not affected by the version of the IUCN Red List used to simulate future extirpations (Fig. S6).

\section{DISCUSSION}

All scenarios simulating a future increase in non-native species introduction and native species extirpation processes 

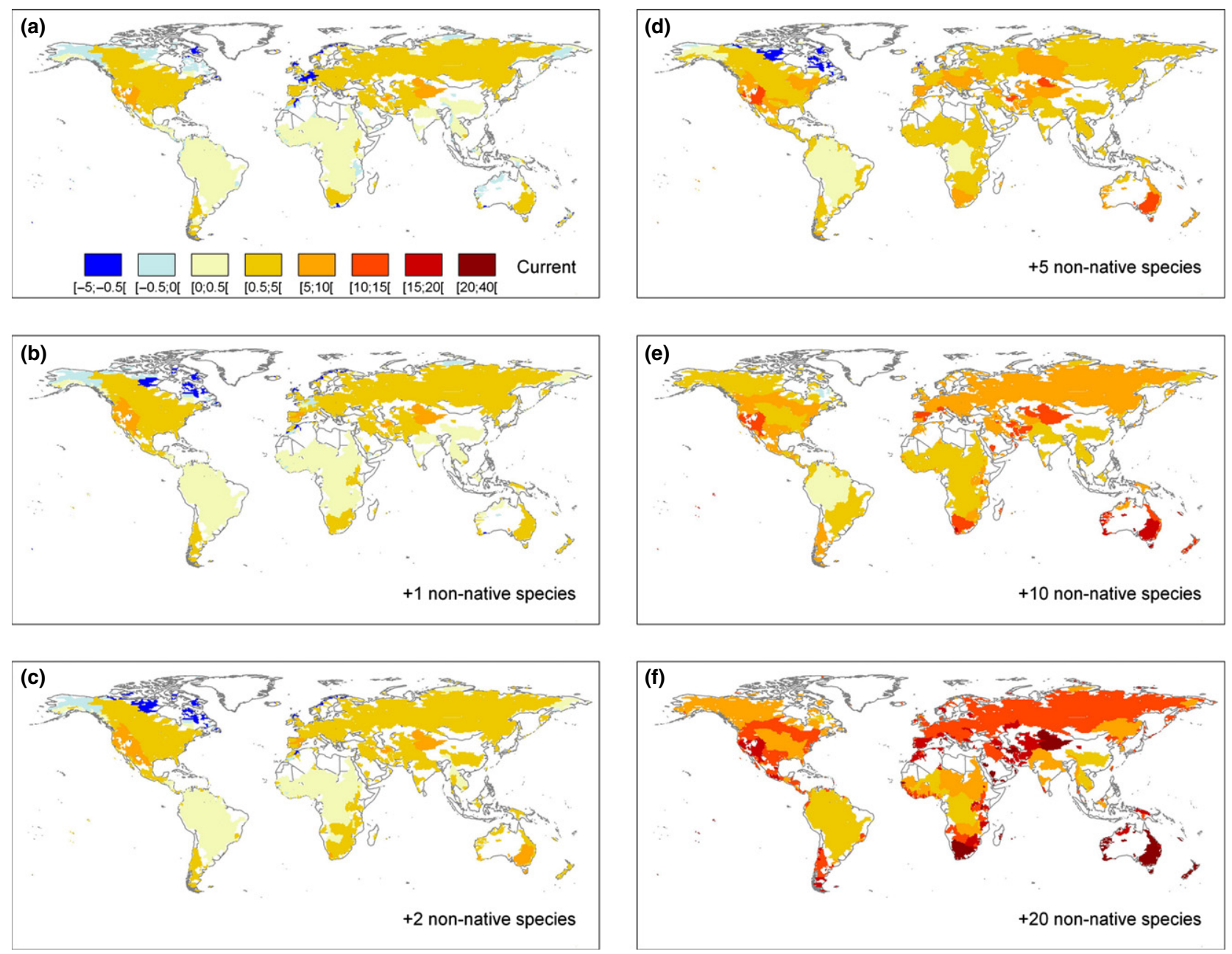

Figure 2 Global maps showing the change in mean taxonomic similarity between each basin and the other basins belonging to the same realm. (a) Observed change from historical to current situation. (b-f) Simulated future change from historical situation under an increasing number of non-native species occurrences in each basin (from 1 to 20) with species selected according to their current frequencies and considering the extirpation of all fish species listed as vulnerable by the IUCN in 2004 (scenarios 'Ex04-InFa' in Table 1). The proportions of basins in each class of intensity of change in taxonomic similarity in each realm are provided on Fig. 3.

predict that taxonomic similarity would increase markedly at the three spatial scales considered (Figs 1-3, Figs S2-S5). These future trends contrasted drastically with the low change in taxonomic similarity $(<0.5 \%)$ observed at the world scale from the pre-industrial to the current period (Villéger et al., 2011). Similarly, taxonomic uniqueness, which was historically high $(80 \%)$ due to important endemism levels in river basins (Tedesco et al., 2012), is predicted to drop below $10 \%$ in all our scenarios confirming the future erosion of the historical high dissimilarity among faunas (Leprieur et al., 2011; Villéger et al., 2011).

Furthermore, the extirpation of all the species listed as threatened would have a negligible role on future change in similarity compared with the increase in non-native species occurrences (Fig. 1, Table 2, Figs S2-S4 \& Fig. S6), which confirms the dominant role of non-native species introductions in driving homogenization observed for the current situation (Villéger et al., 2011). The two assumptions about introduction pressure combined with the two modes of selection of the non-native species introduced provide similar predictions at the world and realms scales, that is, a trend towards taxonomic homogenization. However, slight differences in the intensity of homogenization are expected among scenarios for some regions (Fig. 1, Figs S2-S5). For instance, the Afrotropical realm could experience a stronger increase in taxonomic similarity when the introduction pressure is dependent of current native richness, which is indeed high compared with other realms. For all levels of introduction pressure, the scenarios considering random future introductions forecast lower levels of homogenization than scenarios considering frequency-dependent introductions (Fig. 1). Indeed, as current number of occurrences of non-native species is uneven (Table S1), the probability of introducing a species already present in several river basins in additional 

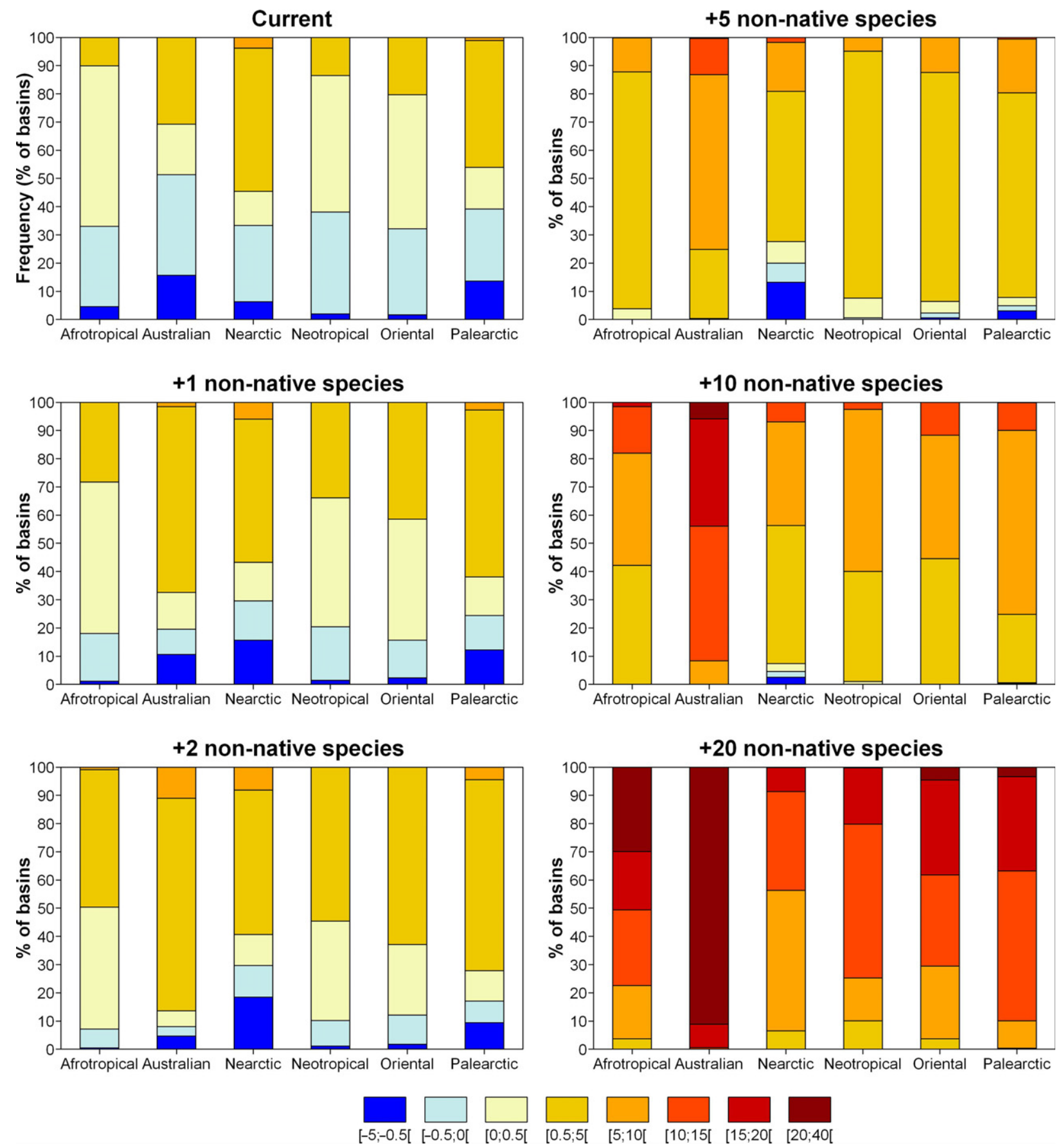

Figure 3 Distribution of change in mean taxonomic similarity per river basin for current and future situations. See Fig. 2 legend for details about scenarios of future change in species composition.

river basins is higher when considering frequency-dependent future introductions. Random introductions may, on the opposite, promote differentiation at least when few nonnative species are added (Fig. S3).

The scenarios simulating a fixed number of additional non-native species (i.e. non-native species introductions not dependent on native species richness) and a frequencydependent probability of introduction appear the most probable scenarios for most river basins. Indeed, previous studies have found that, at the river basin scale, the nonnative species richness is mainly driven by human activities, whereas biotic acceptance or biotic resistance has weak effects (Leprieur et al., 2008a; Blanchet et al., 2009; Hermoso et al., 2012). Furthermore, the non-native species already established in numerous river basins will have the highest probability to increase their number of occurrences in the 
Table 2 Effects of non-native species richness, extirpation and realm on the future change in average taxonomic similarity in river basins

\begin{tabular}{lllr}
\hline & $\begin{array}{l}\text { Degrees of } \\
\text { freedom }\end{array}$ & $F$-value & $P$-value \\
\hline Extirpation & 1,58 & 2.92 & 0.094 \\
$\begin{array}{l}\text { Realm } \\
\text { Number of additional }\end{array}$ & 5,53 & 195 & $<0.001$ \\
$\quad 1,52$ & 6454 & $<0.001$ \\
$\quad$ non-native species & & & $<0.001$ \\
$\begin{array}{l}\text { Realm } \times \text { Number of } \\
\text { additional non-native } \\
\text { species }\end{array}$ & 5,47 & 150 & \\
\hline
\end{tabular}

A generalized linear model (GLM) was applied to the simulated change in average pairwise taxonomic similarity (dTS) values ( $n=60)$ obtained under scenarios considering both an increase of non-native species richness (NNSR) independently of current species richness and a frequency-dependent species choice, but differing by accounting for extirpation of threatened species or not (EX). A full model including all interaction terms was first applied (dTS $\sim$ EX $\times$ Realm $\times$ NNSR). The simplified model presented here accounts for the significant interaction only ( $\mathrm{dTS} \sim \mathrm{EX}+$ Realm $\times$ NNSR).

near future through natural expansion of their distribution range (Kolar \& Lodge, 2001; Olden et al., 2006b; Britton et al., 2011). Moreover, the non-native species most frequently introduced are also fish species that are of interest for aquaculture, recreational fishing or ornamental purposes (Fig. S1) (Mack et al., 2000; Alcaraz et al., 2005; Clavero, 2011; Villéger et al., 2011). These species are thus the most prone to be introduced in additional river basins. However, as the processes underlying non-native species spread can differ among river basins or biogeographic realms (Blanchet et al., 2009), mixing introductions scenarios might help providing more realistic predictions (Rahel, 2010; Clavero, 2011).

Although all our simulations predict a sharp increase in taxonomic similarity for the six realms, some discrepancies can be noticed among realms concerning the intensity of change. Three main patterns emerge (Figs 1-3): (1) the Nearctic realm where taxonomic similarity increase shows the weakest slope, (2) the Afrotropical, Neotropical, Oriental and Palearctic realms where taxonomic similarity increase has intermediate slopes and (3) the Australian realm where taxonomic similarity has the steepest increase. In other words, the realm that is currently the most homogeneous (i.e. the Nearctic realm) will not display the strongest increase in taxonomic similarity in the near future. In contrast, Southern Hemisphere realms that are currently less invaded than the Nearctic and Palearctic realms (Blanchet et al., 2009) and hence weakly concerned by change in taxonomic similarity are the most sensitive to taxonomic homogenization. This trend is particularly marked for the Australian realm, which has the particularity of having both a low native richness and a high proportion of exotic species originating from Eurasia and North America (Fig. S1).
The range of non-native species richness used in our scenarios is consistent with, and even lower than, the current non-native species richness in most rivers of the world (Leprieur et al., 2008a) and might be reached within a few decades if current introduction trends are not mitigated (Taylor \& Irwin, 2004; Vander Zanden, 2005; Hulme et al., 2009; Butchart et al., 2010). Indeed, the introduction trend is currently accelerating world-wide (Butchart et al., 2010). For instance, Vander Zanden (2005) reported that since 1950 the number of aquatic non-native species in the Great Lakes has increased by more than $100 \%$ (from 80 to ca. 170 species). Nevertheless, scenarios accounting for future economical activities, legal limitations on species transport and ecological processes (abiotic and biotic) would improve the quality of the predictions (Clavero, 2011). In addition, our scenarios supposed a conservative pool of non-native species, which may be unlikely, as some new species would certainly become non-native in the next decades, despite legislative restrictions refraining new species introductions in most regions (McAusland \& Costello, 2004; Hulme et al., 2009). Global change through climate warming and habitat degradation might also trigger non-native species spread, as it is known to favour the extension of non-native species spatial range and non-native establishment (Rahel \& Olden, 2008; Britton et al., 2011; Hermoso et al., 2012). Indeed, non-native species are prone to colonize vacant niches liberated by species extirpations or new niches created by human disturbances (Kennard et al., 2005; Hobbs et al., 2006). Some non-native species would also extend their spatial distribution, which is currently often limited by their thermal niche (Rahel \& Olden, 2008; Walther et al., 2009; Bradley et al., 2012). Further studies are thus required to profile the future successful non-native species as well as to predict their future distribution (Mack et al., 2000; Marchetti et al., 2004; McAusland \& Costello, 2004; Alcaraz et al., 2005; Simberloff et al., 2005; Clavero, 2011).

The predictions of our scenarios should be considered with caution as the number of species prone to extirpation in the future might be underestimated. Indeed, the IUCN status is only documented for a low proportion of fish species (IUCN 2014). Although most studies predict higher extinction rates in the future (Ricciardi \& Rasmussen, 1999; Millennium Ecosystem Assessment, 2005; Rodrigues et al., 2006; Maclean \& Wilson, 2011), these studies do not identify the species at risk, and therefore such information could not be integrated in our simulations. More realistic scenarios, that take into account human disturbances affecting freshwater ecosystems characteristics (temperature, flow, pollution, connectivity), need to be developed for predicting the future composition of fish assemblages. Indeed, global change is expected to favour spatial range contraction of some native species (Engler et al., 2011; Thuiller et al., 2011; Bellard et al., 2012) leading in the extreme cases to their extirpation from entire river basins, but such studies are still limited to regional scales (Buisson et al., 2008; Olden et al., 2008b). However, recent studies using an empirically derived 'extinction-area' curve for riverine fishes world-wide estimated (1) 
very low natural extinction rates, that is, median extinction rates $=0.000796 \mathrm{sp}^{-1}$ year $^{-1}$ for 91,949 drainage basins (Tedesco et al., 2013) and (2) a $\sim 39$ times increase of these extinction rates during the last 110 years in drainage basins of the two most strongly human-impacted regions of the world (Western Europe and North America) (Dias et al., unpublished result). Taken together, these two recent results strongly suggest that natural and/or anthropogenic extinctions are long-time processes that should only marginally affect future homogenization trends at large spatial scales compared with the influence of future non-native species introductions.

\section{CONCLUSIONS}

The dissimilarity between species assemblages is a key facet of biodiversity reflecting biogeography and evolutionary history of assemblages (McKnight et al., 2007; Leprieur et al., 2011; Tedesco et al., 2012). Human activities and the consecutive species extirpations and introductions have already modified the historical patterns, and the forecasted increase of these processes in the next decades (Mack et al., 2000; Hulme et al., 2009; Leprieur et al., 2009) may blur the high historical taxonomic dissimilarity between distant regions. As taxonomic dissimilarity patterns are used to set conservation priorities (Steinitz et al., 2005; Jost et al., 2010), it is important to anticipate the future composition of assemblages to design optimal conservation plan. Towards this aim, further developments are needed to improve predictions on future native species extirpations and non-native introductions following anthropogenic disturbances and policies. Besides these conservation issues, we also need deeper fundamental knowledge about consequences of this human-induced change in beta-diversity on ecosystem functioning (Pasari et al., 2013). Developing a functional view of assemblages and assessing changes in functional similarity between assemblages (Pool \& Olden, 2012; Matsuzaki et al., 2013) is the next step towards this aim.

\section{ACKNOWLEDGEMENTS}

We thank three anonymous referees and the editors for their constructive comments that helped us to improve our manuscript. We thank Peter Winterton for correcting the English. This work was supported by the EU BIOFRESH project (7th Framework European program, Contract No. 226874). This work has been carried out in the laboratory EDB, part of the 'Laboratoires d'Excellence' (LABEX) entitled TULIP (ANR10-LABX-41) and CEBA (ANR-10-LABX-25).

\section{REFERENCES}

Alcaraz, C., Vila-Gispert, A. \& García-Berthou, E. (2005) Profiling invasive fish species: the importance of phylogeny and human use. Diversity and Distributions, 11, 289-298.
Baillie, J.E.M., Hilton-Taylor, C. \& Stuart, S. (2004) 2004 IUCN Red List of threatened species: a global assessment. IUCN (International Union For Conservation Of Nature), Gland (Switzerland) and Cambridge (UK).

Bellard, C., Bertelsmeier, C., Leadley, P., Thuiller, W. \& Courchamp, F. (2012) Impacts of climate change on the future of biodiversity. Ecology Letters, 15, 365-377.

Blackburn, T.M., Pyšek, P., Bacher, S., Carlton, J.T., Duncan, R.P., Jarošík, V., Wilson, J.R.U. \& Richardson, D.M. (2011) A proposed unified framework for biological invasions. Trends in Ecology and Evolution, 26, 333-339.

Blanchet, S., Leprieur, F., Beauchard, O., Staes, J., Oberdorff, T. \& Brosse, S. (2009) Broad-scale determinants of non-native fish species richness are context-dependent. Proceedings of the Royal Society B: Biological Sciences, 276, 2385-2394.

Blanchet, S., Grenouillet, G., Beauchard, O., Tedesco, P.A., Leprieur, F., Dürr, H.H., Busson, F., Oberdorff, T. \& Brosse, S. (2010) Non-native species disrupt the worldwide patterns of freshwater fish body size: implications for Bergmann's rule. Ecology Letters, 13, 421-431.

Bradley, B.A., Blumenthal, D.M., Early, R., Grosholz, E.D., Lawler, J.J., Miller, L.P., Sorte, C.J., D'Antonio, C.M., Diez, J.M., Dukes, J.S., Ibanez, I. \& Olden, J.D. (2012) Global change, global trade, and the next wave of plant invasions. Frontiers in Ecology and the Environment, 10, 20-28.

Britton, J.R., Gozlan, R.E. \& Copp, G.H. (2011) Managing non-native fish in the environment. Fish and Fisheries, 12, 256-274.

Brosse, S., Beauchard, O., Blanchet, S., Dürr, H.H., Grenouillet, G., Hugueny, B., Lauzeral, C., Leprieur, F., Tedesco, P.A., Villéger, S. \& Oberdorff, T. (2013) Fish-SPRICH: a database of freshwater fish species richness throughout the World. Hydrobiologia, 700, 343-349.

Buisson, L., Thuiller, W., Lek, S., Lim, P. \& Grenouillet, G. (2008) Climate change hastens the turnover of stream fish assemblages. Global Change Biology, 14, 2232-2248.

Butchart, S.H.M., Walpole, M., Collen, B. et al. (2010) Global biodiversity: indicators of recent declines. Science, 328, 1164-1168.

Clavero, M. (2011) Assessing the risk of freshwater fish introductions into the Iberian Peninsula. Freshwater Biology, 56, 2145-2155.

Clavero, M. \& García-Berthou, E. (2006) Homogenization dynamics and introduction routes of invasive freshwater fish in the Iberian Peninsula. Ecological Applications, 16, 2313-2324.

Duncan, J.R. \& Lockwood, J.L. (2001) Spatial homogenization of the aquatic fauna of Tennessee: extinction and invasion following land use change and habitat alteration.Biotic homogenization (ed. by J.L. Lockwood and M.L. McKinney), pp. 245-257. Kluwer Academic/Plenum Publishers, New York, NY.

Ellis, E.C., Klein Goldewijk, K., Siebert, S., Lightman, D. \& Ramankutty, N. (2010) Anthropogenic transformation of 
the biomes, 1700 to 2000. Global Ecology and Biogeography, 19, 589-606.

Engler, R., Randin, C.F., Thuiller, W. et al. (2011) 21st century climate change threatens mountain flora unequally across Europe. Global Change Biology, 17, 2330-2341.

Gozlan, R.E., Britton, J.R., Cowx, I. \& Copp, G.H. (2010) Current knowledge on non-native freshwater fish introductions. Journal of Fish Biology, 76, 751-786.

Hermoso, V., Clavero, M. \& Kennard, M.J. (2012) Determinants of fine-scale homogenization and differentiation of native freshwater fish faunas in a Mediterranean Basin: implications for conservation. Diversity and Distributions, 18, 236-247.

Hobbs, R., Arico, S. \& Aronson, J. (2006) Novel ecosystems: theoretical and management aspects of the new ecological world order. Global Ecology and Biogeography, 15, 1-7.

Hulme, P.E., Pyšek, P., Nentwig, W. \& Vilà, M. (2009) Will threat of biological invasions unite the European Union? Science, 324, 40-41.

IUCN International Union For Conservation Of Nature (2014) Available at: www.iucnredlist.org. (accesed 3 March 2014).

Jost, L., DeVries, P., Walla, T., Greeney, H., Chao, A. \& Ricotta, C. (2010) Partitioning diversity for conservation analyses. Diversity and Distributions, 16, 65-76.

Kennard, M.J., Arthington, A.H., Pusey, B.J. \& Harch, B.D. (2005) Are alien fish a reliable indicator of river health? Freshwater Biology, 50, 174-193.

Kolar, C.S. \& Lodge, D.M. (2001) Progress in invasion biology: predicting invaders. Trends in Ecology and Evolution, 16, 199-204.

Leprieur, F., Beauchard, O., Blanchet, S., Oberdorff, T. \& Brosse, S. (2008a) Fish invasions in the world's river systems: when natural processes are blurred by human activities. PLoS Biology, 6, e28.

Leprieur, F., Beauchard, O., Hugueny, B., Grenouillet, G. \& Brosse, S. (2008b) Null model of biotic homogenization: a test with the European freshwater fish fauna. Diversity and Distributions, 14, 291-300.

Leprieur, F., Brosse, S., García-Berthou, E., Oberdorff, T., Olden, J.D. \& Townsend, C.R. (2009) Scientific uncertainty and the assessment of risks posed by non-native freshwater fishes. Fish and Fisheries, 10, 88-97.

Leprieur, F., Tedesco, P.A., Hugueny, B., Beauchard, O., Dürr, H.H., Brosse, S. \& Oberdorff, T. (2011) Partitioning global patterns of freshwater fish beta diversity reveals contrasting signatures of past climate changes. Ecology Letters, 14, 325-334.

Mack, R.N., Simberloff, D., Lonsdale, W.M., Evans, H., Clout, M. \& Bazzaz, F.A. (2000) Biotic invasions: causes, epidemiology, global consequences, and control. Ecological Applications, 10, 689-710.

Maclean, I.M.D. \& Wilson, R.J. (2011) Recent ecological responses to climate change support predictions of high extinction risk. Proceedings of the National Academy of Sciences USA, 108, 12337-12342.
Marchetti, M.P., Moyle, P.B. \& Levine, R. (2004) Invasive species profiling? Exploring the characteristics of nonnative fishes across invasion stages in California. Freshwater Biology, 49, 646-661.

Matsuzaki, S.S., Sasaki, T. \& Akasaka, M. (2013) Consequences of the introduction of exotic and translocated species and future extirpations on the functional diversity of freshwater fish assemblages. Global Ecology and Biogeography, 22, 1071-1082.

McAusland, C. \& Costello, C. (2004) Avoiding invasives: trade-related policies for controlling unintentional exotic species introductions. Journal of Environmental Economics and Management, 48, 954-977.

McKnight, M.W., White, P.S., McDonald, R.I., Lamoreux, J.F., Sechrest, W., Ridgely, R.S. \& Stuart, S.N. (2007) Putting beta-diversity on the map: broad-scale congruence and coincidence in the extremes. PLoS Biology, 5, e272.

Millennium Ecosystem Assessment (2005) Ecosystems and human well-being. World Resources Institute, Washington, DC.

Olden, J.D. (2006) Biotic homogenization: a new research agenda for conservation biogeography. Journal of Biogeography, 33, 2027-2039.

Olden, J.D. \& Poff, N.L. (2003) Toward a mechanistic understanding and prediction of biotic homogenization. The American Naturalist, 162, 442-460.

Olden, J.D. \& Poff, N.L. (2004) Ecological processes driving biotic homogenization: testing a mechanistic model using fish faunas. Ecology, 85, 1867-1875.

Olden, J.D. \& Rooney, T.P. (2006) On defining and quantifying biotic homogenization. Global Ecology and Biogeography, 15, 113-120.

Olden, J.D., Poff, N.L. \& Bestgen, K.R. (2006a) Life-history strategies predict fish invasions and extirpations in the Colorado River Basin. Ecological Monographs, 76, 25-40.

Olden, J.D., Poff, N.L. \& McKinney, M.L. (2006b) Forecasting faunal and floral homogenization associated with human population geography in North America. Biological Conservation, 127, 261-271.

Olden, J.D., Hogan, Z.S. \& VanderZanden, M.J. (2007) Small fish, big fish, red fish, blue fish: size-biased extinction risk of the world's freshwater and marine fishes. Global Ecology and Biogeography, 16, 694-701.

Olden, J.D., Kennard, M.J. \& Pusey, B.J. (2008a) Species invasions and the changing biogeography of Australian freshwater fishes. Global Ecology and Biogeography, 17, 2537.

Olden, J.D., Poff, N.L. \& Bestgen, K.R. (2008b) Trait synergisms and the rarity, extirpation, and extinction risk of desert fishes. Ecology, 89, 847-856.

Pasari, J.R., Levi, T., Zavaleta, E.S. \& Tilman, D. (2013) Several scales of biodiversity affect ecosystem multifunctionality. Proceedings of the National Academy of Sciences USA, 110, 10219-10222.

Pimentel, D., Zuniga, R. \& Morrison, D. (2005) Update on the environmental and economic costs associated with 
alien-invasive species in the United States. Ecological Economics, 52, 273-288.

Pool, T.K. \& Olden, J.D. (2012) Taxonomic and functional homogenization of an endemic desert fish fauna. Diversity and Distributions, 18, 366-376.

R Core Team (2013) R: a language and environment for statistical computing. R Foundation for Statistical Computing, Vienna, Austria.

Rahel, F.J. (2000) Homogenization of Fish Faunas Across the United States. Science, 288, 854-856.

Rahel, F.J. (2007) Biogeographic barriers, connectivity and homogenization of freshwater faunas: it's a small world after all. Freshwater Biology, 52, 696-710.

Rahel, F.J. (2010) Homogenization, differentiation, and the widespread alteration of fish faunas. American Fisheries Society Symposium, 73, 311-326.

Rahel, F.J. \& Olden, J.D. (2008) Assessing the effects of climate change on aquatic invasive species. Conservation Biology, 22, 521-533.

Ricciardi, A. \& Rasmussen, J.B. (1999) Extinction rates of North American Freshwater Fauna. Conservation Biology, 13, 1220-1222.

Rodrigues, A.S.L., Pilgrim, J.D., Lamoreux, J.F., Hoffmann, M. \& Brooks, T.M. (2006) The value of the IUCN Red List for conservation. Trends in Ecology and Evolution, 21, 7176.

Rooney, T.P., Wiegmann, S.M., Rogers, D.A. \& Waller, D.M. (2004) Biotic impoverishment and homogenization in unfragmented forest understory communities. Conservation Biology, 18, 787-798.

Sala, O.E., Chapin, F.S., Armesto, J.J., Berlow, E., Bloomfield, J., Dirzo, R., Huber-Sanwald, E., Huenneke, L.F., Jackson, R.B., Kinzig, A., Leemans, R., Lodge, D.M., Mooney, H.A., Oesterheld, M., Poff, N.L., Sykes, M.T., Walker, B.H., Walker, M. \& Wall, D.H. (2000) Global biodiversity scenarios for the year 2100. Science, 287, 1770-1774.

Shaw, J.D., Spear, D., Greve, M. \& Chown, S.L. (2010) Taxonomic homogenization and differentiation across Southern Ocean Islands differ among insects and vascular plants. Journal of Biogeography, 37, 217-228.

Simberloff, D., Parker, I. \& Windle, P. (2005) Introduced species policy, management, and future research. Frontiers in Ecology and the Environment, 3, 12-20.

Spear, D. \& Chown, S.L. (2008) Taxonomic homogenization in ungulates: patterns and mechanisms at local and global scales. Journal of Biogeography, 35, 1962-1975.

Steinitz, O., Heller, J., Tsoar, A., Rotem, D. \& Kadmon, R. (2005) Predicting regional patterns of similarity in species composition for conservation planning. Conservation Biology, 19, 1978-1988.

Taylor, B.W. \& Irwin, R.E. (2004) Linking economic activities to the distribution of exotic plants. Proceedings of the National Academy of Sciences USA, 101, 17725-17730.

Tedesco, P.A., Leprieur, F., Hugueny, B., Brosse, S., Dürr, H.H., Beauchard, O., Busson, F. \& Oberdorff, T. (2012)
Patterns and processes of global riverine fish endemism. Global Ecology and Biogeography, 21, 977-987.

Tedesco, P.A., Oberdorff, T., Cornu, J.-F., Beauchard, O., Brosse, S., Dürr, H.H., Grenouillet, G., Leprieur, F., Tisseuil, C., Zaiss, R. \& Hugueny, B. (2013) A scenario for impacts of water availability loss due to climate change on riverine fish extinction rates. Journal of Applied Ecology, 50, 1105-1115.

Thuiller, W., Lavergne, S., Roquet, C., Boulangeat, I., Lafourcade, B. \& Araujo, M.B. (2011) Consequences of climate change on the tree of life in Europe. Nature, 470, 531-534.

Vander Zanden, M.J. (2005) The success of animal invaders. Proceedings of the National Academy of Sciences USA, 102, 7055-7056.

Villéger, S. \& Brosse, S. (2012) Measuring changes in taxonomic dissimilarity following species introductions and extirpations. Ecological Indicators, 18, 552-558.

Villéger, S., Blanchet, S., Beauchard, O., Oberdorff, T. \& Brosse, S. (2011) Homogenization patterns of the world's freshwater fish faunas. Proceedings of the National Academy of Sciences USA, 108, 18003-18008.

Walther, G.-R., Roques, A., Hulme, P.E. et al. (2009) Alien species in a warmer world: risks and opportunities. Trends in Ecology and Evolution, 24, 686-693.

Winter, M., Schweiger, O., Klotz, S., Nentwig, W., Andriopoulos, P., Arianoutsou, M., Basnou, C., Delipetrou, P., Didziulis, V., Hejda, M., Hulme, P.E., Lambdon, P.W., Pergl, J., Pyšek, P., Roy, D.B. \& Kühn, I. (2009) Plant extinctions and introductions lead to phylogenetic and taxonomic homogenization of the European flora. Proceedings of the National Academy of Sciences USA, 106, 21721-21725.

\section{SUPPORTING INFORMATION}

Additional Supporting Information may be found in the online version of this article:

Figure S1 Occurrence frequencies of the ten most introduced fish species in the six biogeographic realms.

Figure S2 Historical, current and future taxonomic uniqueness and mean taxonomic similarity among pairs of fish faunas.

Figure S3 Historical, current and future homogenization and differentiation frequencies among pairs of fish faunas.

Figure S4 Historical, current and future trends of the median, skewness and kurtosis of the taxonomic similarity among pairs of fish faunas.

Figure S5 Distribution of future change in mean taxonomic similarity per river basin.

Figure S6 Future taxonomic uniqueness and future mean taxonomic similarity under three levels of future extirpation. 
Table S1 Present patterns of species extirpations and introductions in the six biogeographic realms.

\section{BIOSKETCH}

Sébastien Villéger is currently a researcher in the laboratory 'Écologie des Systèmes Marins Côtiers' (Centre National de la Recherche Scientifique, Montpellier, France). During his postdoctoral position in the laboratory 'Evolution et Diversité Biologique' (University of Toulouse, France), he used taxonomic and functional approaches to assess the impact of non-native species on biotic homogenization of fish communities.

Author contributions: all authors conceived the ideas; O.B., S.Br. and T.O. collected the data; S.V. analysed the data. S.V., S.Bl and S.Br. led the writing and all authors contributed to the final manuscript.

Editor: Jonathan Jeschke 